\title{
Prevailing Practices in Handling Serials
}

The supervisor of the serials section, Washington Square Library, New York University, and the reference assistant in charge of the serials division, College of the City of New York Library, discuss present trends in work with serials.

CoIEntists insist that the first step in $\mathcal{S}$ the solution of any problem is the recognition and formulation of the problem. At the first meeting of the American Library Association, the problem of the care and handling of serial publications was poised as follows:

If railway companies, and coal companies, and hospitals, and colleges, and penitentiaries, and benevolent institutions of every sort-to say nothing of historical societies and library companies-keep publishing their annual reports for another century as they publish them now, may it not require the most active labor of the best librarian in America, to collect, to preserve, to bind, to arrange, and catalogue them all? Yet few books are more instructive as to special matters; few more of ten wanted by a large class of readers. ${ }^{1}$

\section{Serials Then and Now}

Although the first step was taken some sixty-three years ago, little real progress has been made toward a solution until within the last five years. Having for the most part obtained insight into the vagaries of periodical titles, formats, etc.,

${ }^{1}$ Library Journal I:94, Nov. 30, 1876. the profession drifted into the practice of relegating to the last assistant hired, the work on periodicals. It was felt that since most of the work consisted merely in checking in current numbers, anybody would do. But now, as serial publications pour into the libraries, and as the line of demarcation between the multiform serial and the ordinary periodical becomes more difficult to draw, the situation is virtually reversed. The work now calls for highly competent and well trained librarians.

In 1935, J. Harris Gable spoke to the College and Reference Section of the American Library Association on serials procedures. $\mathrm{He}$ stressed the increasing difficulty of the problem and recommended:

The grouping of all serials functions ... for the following reasons: (I) the work may be more easily and efficiently done where the records are kept, (2) the work may be done by trained serials workers, (3) the evil of over-departmentalization cannot appear, (4) there is no unnecessary duplication of records, (5) the same persons handle all the necessary records, thus eliminating possibility of error or duplication of material, and (6) the service to the public is greatly improved. ${ }^{2}$

In the course of his report, Mr. Gable indicated that only one institution had taken any steps in this direction. $\mathrm{He}$ erred in minimizing the progress that had ${ }^{2}$ Gable, J. Harris. "The New Serials Depart.
ment." Library Journal 60:867-7 I, Nov. I 5, 1935. 165 
been made. Actually several institutions had already investigated the possibilities of centralization and had acted upon them in varying degrees. Gable made service to the public his sixth and last point in planning for a reorganization of serials procedures; it is our feeling that first place should be given to the improvement of service to the public, and that economy and ease of operation are secondary to this end. The importance of this distinction can best be realized when we glance (as we soon shall) at some of the attempts made to reorganize the work.

This report ostensibly is on prevailing practices in the handling and care of serials. To give the picture as asked for, would be like asking a blind man in a dark room to find a black cat that is not there. As a result of the survey, we do feel that there is a decided trend toward centralization. This trend has taken so many forms that it can hardly be called a prevailing practice.

\section{Present Practices}

Let us look at the two extremes in present practices, and from them, go on to the outlines of some of the means. On the one hand, we find the librarian of a large college library reporting:

We are currently receiving in the neighborhood of only 500 serials. We have no separate periodical or serials room or department so our serials are handled like other accessions, being ordered by the order department, cataloged by the catalog department, and made available for use through the circulation department.

At the other extreme, we find a university library where all serial publications are circulated from one point, the serials department. This department is made responsible for reference and circulation work, cataloging and classification, preparation for binding, checking in, and acquisition-including purchase, gift, and exchanges.

Working away from the point of extreme centralization, we find a large college library in which the serials division is responsible for the circulation and reference work, as well as for acquisition and binding, but not for the cataloging and classification of serials. At still another, all the preparatory work is done by the serials division, but it is not responsible for the circulation and reference functions. Looking elsewhere, we find libraries in which a special division is responsible for the work with periodicals, but not other serials.

A surprising diversity of practice is found in the distinction made among the various types of serial publications. Excepting those libraries with organized serials divisions, we find it a common practice to have a periodical division or reading room. In most instances, this division is responsible for the checking-in and the circulation of periodical material; in some, it is also responsible for the preparation of this material for the bindery. In other words, it has been a common practice in the past to distinguish periodicals from all other types of library material. With the increase of the publication of new and diverse types of serials, there has come into being an obvious consciousness of the fact that serial publications are different from books. As a result, we find many distinctions in the treatment of periodicals, serials, continuations, and serial government publications. These distinctions take many forms; some libraries have a periodical division, document division, continuation division, a serial division, and a gift and exchange division. In these libraries 
the department chosen to handle the material is determined not only by form but by source as well. Part of a set is ordered and handled in one department, at least as far as its early processes are concerned; another part of the same set is received by gift or exchange and passes through another department for the early stages of preparation.

If there is any reason at all for distinguishing periodicals from books insofar as treatment and handling are concerned, there is more reason for making the distinction for all serial publications in their entirety. Periodicals are by definition fairly regular publications, appearing at specified intervals. True though it is that changes in format, title, and frequency raise problems now and then, these problems do not compare in difficulty with the problems normally encountered in the use, acquisition, cataloging, and classification of irregular serial publications. If distinctions are made among periodicals, serials, continuations, and government documents, the distinction in and of itself breeds a difficulty inherent in the fact that, regardless of the care with which definitions are prepared, borderline cases must be numerous. A broad line of demarcation, that between serial and nonserial material, offers the least possible source of difficulty.

\section{Present Trend}

All in all, we find that twelve of twenty-two large college and university libraries have a serials division which is staffed by from three to nineteen persons. Seven of these are independent departments which are coordinated in various ways with other departments of the library. Substantially the same situation, with some variations, is found among the medium-sized college libraries where seven

MARCH, 1940 out of fifteen libraries reported that they had a serials division. In the small college library, and in the medium and small public libraries, the situation is somewhat different. In these instances, there is a much greater degree of natural centralization of duties, by virtue of the fact that the staff is small. The result is that the benefits of centralization of duties are present without formal organization.

\section{A Rare Approach}

We have pointed out that the problems involved in the handling and care of serials have long been recognized. There have been several attempts made to meet these problems. These remedial measures, as a rule, have been taken at the point of immediate provocation, viz., the acquisition of material. Rare indeed has been the approach from the reader's point of view. The incomplete, the inaccurate, the confused, the inverted reference to serial publications and the resultant difficulties encountered by the reader have not yet struck the library administration where it would be most evident. Is it possible to achieve a simplification of procedure which will satisfy at once the needs of its readers and simplify the library's administrative problems?

If the approach is any other but that of service to the reader, we find situations wherein a special assistant (or assistants) is made responsible for the acquisition of serials. Special records for serials only are kept in the acquisition department. When the problem reaches the catalog department, we find a special assistant (or assistants) assigned to meet it. Frequently we find a special serials catalog designed to meet the problem. By the time the material is made available for use, additional records, available to reference 
assistants and to the reader, are found necessary. We find plans wherein special lists of serials are kept and checked in the reference division. We find systems wherein each time new pieces are added to the collection, their acquisition must be noted on each entry for the set in the public catalog. We find that each piece that offers a special problem is delayed on its way through the mill, and among serials there are many pieces that offer special problems. Another perplexing problem arises with such a set-up. Departmental bias must of necessity play its part in varying degrees in the treatment of the material.

What happens when we centralize these various steps in one department? It is at the point where circulation and reference work meet that centralization makes itself felt most in the college library. Reference as to serials takes many and varied forms. The sources of these references may be footnotes in books or articles, an offhand remark by an instructor or student, or more formal bibliographies, or indexes. In some cases the source may be an analytic entry in the library catalog. In many instances the source may be responsible for an incomplete reference; in others, the reader may present an inaccurate reference. Reference librarians are all familiar with requests such as: "League of $\mathrm{Na}$ tions. V I, I937" when the reader wants League of Nations. Mixed Committee on Nutrition. Interim Report V I ; or, the Thirty-first Yearbook of the N.E.A. when the student means the N.S.S.E. Thirty-first Yearbook. We all know the student who looks under " $D$ " in the cata$\log$ for the Department of Elementary School Principals Yearbook, which is entered under National Education Association-Department of Elementary School Principals. Then there is the instructor who refers his students to "a bulletin of the University of Iowa," which issues some twenty different series. Examples such as these could be multiplied indefinitely. The fact remains that all too often providing the reader with needed material requires a thorough knowledge of the serials collection. Such a knowledge can be acquired in a fair-sized library only by those who handle the material frequently and constantly. A member of the staff, who prepares, or sees the original order for material, who plays some part in the checking-in of the material, who is closely associated with cataloging and classification, and with the binding process, must of necessity be more familiar with the material than an assistant who does not see it until it is ready for the shelves.

One of the objections raised to the centralization of work with serials is that many libraires have organized subject departments for the use of readers. One need not interfere with the other. In virtually every instance where there is a serials division in a library, there are also subject departments. The only difference is that the serials division handles these serial publications up to the point where they go to the shelves; only at that time are they sent to the subject department. In other words, serials falling within the scope of a departmental collection are separated from serials in the main collection for purposes of shelving and circulation.

\section{Economy of Administration}

We have stressed service to the reader, but ease and economy from the administrative point of view are also present. They are present because by centralization the duplication of records can be eliminated. The serials catalog is no longer a mere catalog record. It is also 
a record of acquisition, a record of loca- $\lambda$ tion, a record of gaps-in short, a complete record of all the information necessary for the acquisition, treatment, and use of material. Centralization means that the material need not be held up as it travels from point to point. The difficulties attendant upon the handling of a particular title can be resolved once, for all purposes, and the title made available to the reader.

Centralization also means economy because members of the staff are not assigned merely to an acquisition of material, the cataloging of material, or to reference work. They are assigned to all of these. Functional concentration can be shifted to that particular point where the pressure is greatest at any particular time. We all know of the situation, where, at a given time, the acquisition work may be eased, while the catalog department is overwhelmed, or vice versa. We know that there may be a time of the year when little buying or cataloging is done, but there is great pressure on the circulation and reference staff. The result usually is that each department is staffed according to the needs of its peak period of work, with a resultant loss in quiet periods. With centralization, there is no such loss.

As a result of the survey that has been made of methods used in the care and handling of serials in one hundred and twenty-six college, university, and public libraries, we find that complete centralization of functions relating to serials offers the best solution of vexing problems.

\section{Audio-visual Aids and the Library}

\section{(Continued from page 146)}

To buy audio-visual equipment of all the types implied in the outline above, i.e., small portable public address system, radio, silent motion picture projector, stereoscopes or telebinocular, opaque projector, stereopticons, film strip projector, record players to operate at 78 and $33: 3$ r.p.m., sound motion picture projector, sound slide film projector-to buy one of the smaller models of each of these types of apparatus would cost something like $\$ 1000$. As suggested above, in a large institution many departments should duplicate most of this equipment.

\section{Conclusion}

This discussion assumes that audio- visual aids are now too valuable and too widely used to be ignored by any forwardlooking educational agency. It recognizes audio-visual aids as a special type of book, and hence takes the position that the librarian is the logical person to service them, even if this involves some slight additions to his professional training. Certain visual aids have long been library serviced. Recently a few libraries have undertaken a more complete audiovisual program. The Peabody Demonstration School Library is a case in point. We believe that the next decade will see school and college libraries emerging as centers of a finer audio-visual education program than has thus far been developed. 